Artigo recebido em

27/02/2014

Aprovado em

$15 / 03 / 2014$

JOSÉ SALVADOR

FARO

Universidade

Metodista de São

Paulo e

PUC-SP

Professor do curso de Jornalismo da Universidade

Metodista de São Paulo e

da PUC-SP e docente do

Póscom da Umesp. Presidiu

a Intercom no biênio 1997 -

1998. Consultor da Capes, do

CNPq e da Fapesp, é autor

do livro Revista Realidade,

1966-1968. Tempo da

Reportagem na Imprensa

Brasileira (Porto Alegre,

Ulbra/AGE, 1999). E-mail:

jsfaro@jsfaro.net

Estudos em Jornalismo

e Mídia

Vol. 11 No 1

Janeiro a Junho de 2014

ISSNe 1984-6924

\section{A revista Realidade nos anos da mobilização democrática: reportagem e Estado autoritário}

\author{
José Salvador Faro
}

\begin{abstract}
Resumo
$\mathrm{O}$ artigo pretende analisar o papel que a revista Realidade desempenhou no processo de resistência democrática nos anos 60. Criada em 1966, a publicação da Editora Abril, reuniu em sua primeira fase, pelo menos até a edição do AI-5, em 1968, uma equipe de profissionais que enfrentou a progressiva construção e hipertrofia do Estado Autoritário ${ }^{1}$ iniciada com o golpe de 1964. Apesar disso, pela prática da grande reportagem e pelo sentido inusitado e contemporâneo das pautas com as quais trabalhou, a revista acabou se tornando um veículo transgressor do conservadorismo com o qual a aliança civil-militar que derrubou João Goulart pretendia dar significado à nova ordem que se instalou no país. Menos por seu feitio explicitamente político e mais pelos desdobramentos dos novos padrões de cultura que a publicação ajudou a disseminar, grande parte das matérias que foram veiculadas entre 1966 e 1968 testemunham um dos paradoxos do país em processo de modernização prussiana: a dinâmica cultural que resistia ao fechamento institucional. Realidade foi expressão desse conflito e, certamente também por isso, tornou-se instrumento de resistência democrática.
\end{abstract}

Palavras-chave

Revista Realidade, modernização, ditadura militar, cultura, anos 60.

\begin{abstract}
This article intends to analyze the role that magazine Reality played in the process of democratic resistance in the 60's. Created in 1966, this work from the publishing house Abril, reunited in it's first period, at least until the AI-5 edition in 1968, a team of professionals that confronted the progressive construction and hypertrophy of the authoritarian Government initiated with the blow of 1964 . Even tough, by practicing great news and for its unusual and contemporary scripts with witch it worked, the magazine ended up being a transgressor vehicle to the reactionary witch the civil-military alliance that dropped João Goulart pretended to give meaning to the new order that it was installed in this country. Less for its explicit political character and more to the development of new cultural patterns that this publication helped spread, great part of the news that were published between 1966 and 1968 witnessed one of the paradoxes of a country in the process of Prussian modernization; a cultural dynamics that resisted to institutional closure. Reality was an expression of this conflict and, certainly for that, it became an instrument of democratic resistance.

Key words

Reality Magazine, modernization, military dictatorship, culture, 60's, democratic movement

\footnotetext{
1- O conceito de Estado Autoritário é usado aqui nos termos do debate ocorrido nos anos 70 em torno da caracterização das conjunturas políticas que emergiram em diversos países da América Latina atingidos por golpes de ruptura na sua ordem institucional, em especial no âmbito das atividades do Centro Brasileiro de Análise e Planejamento (CEBRAP). No caso do Brasil, em decorrência da preservação de instituições de representação política (ainda que constrangidas fortemente pela conjuntura de repressão instalada depois da queda de Jango) configura-se uma situação híbrida que não chega a caracterizar um regime totalitário pleno - fato que só viria a
} ocorrer após a edição do Ato Institucional n. 5, em dezembro de 1968.
\end{abstract}


O jornalismo investigativo leva muito tempo para ser produzido, ele não é lucrativo, ele nem sempre vende. No entanto, é extremamente necessário para a democracia. (Natália Viana) $)^{2}$
2- Jornalista e diretora da Agência Pública (entrevista publicada em IHU On-Line. Acesso em 4 de fevereiro de 2014).

\section{O tema em discussão}

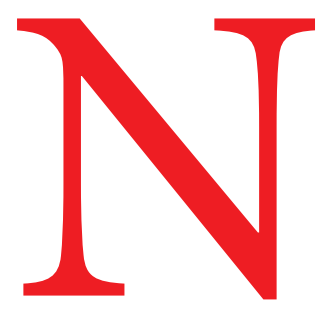

ão é mais do que uma redundância, ainda que necessária para a exposição dos argumentos deste artigo, a ideia de que o Jornalismo é uma instituição da modernidade. A tese é sustentada por correntes variadas de pensamento e de diferentes matrizes filosóficas, mas parece estar consagrada a interpretação segundo a qual a produção noticiosa organizada num veículo de comunicação e operada segundo um conjunto específico de regramentos profissionais é um processo articulado e indissoluvelmente associado ao nascimento da sociedade urbana $\mathrm{e}$ burguesa configurada em um período de longa duração que se dá a partir do século XII (BRIGS \& BURKE, 2004). A melhor síntese feita sobre esse processo histórico, em nossa opinião, é a obra clássica de Jürgen Habermas, Mudança Estrutural da Esfera Pública (1984), na qual o autor identifica na imprensa (termo correspondente à organização institucionalizada do Jornalismo usado aqui genericamente apenas para fins didáticos de exposição) a formação de um espaço virtual de argumentação e deliberação contraposto ao poder do Estado Absoluto, mesmo que o próprio Habermas tenha reconhecido as sucessivas fases pelas quais passou quando muda estruturalmente de papel e se vê transformada em aparelho de interesses privados.

A mudança não é tão pequena assim porque esse deslocamento do interesse público (uma espécie de secundarização que subordina sua percepção ao lugar do acessório e não ao lugar do fundamental) afeta a racionalidade política do Jornalismo que se vê premido por injunções de duas ordens que atuam no seu interior em direções opostas: a primeira, decorrente dos postulados doutrinários que o constituíram como campo profissional e que o atraem para um alinhamento de coerência com os fundamentos liberais que lhe deram origem; a segunda, como consequência da nova realidade econômica que os jornais passaram a viver no desdobramento da própria dinâmica do capitalismo, e que os afasta daqueles fundamentos. Exceto nos países que ensaiaram o modo socialista de produção ao longo do século XX com contradições diversas e peculiares que não cabem ser analisadas aqui -, todo o espectro da imprensa organizada sob a forma de empresas jornalísticas privadas viveu - e ainda vive - essa tensão.

No entanto, a constatação não é o bastante: se o Jornalismo é dispositivo da modernidade no plano da sua operacionalidade noticiosa, ele o é também no plano das configurações simbólicas e amplas de sentido que sua presença provoca na vida social. $\mathrm{O}$ veículo jornalístico (seja ele revista ou jornal) é um signo e transfere essa sua dimensão para todos os componentes que o integram: os textos em seus diversos gêneros e formatos, verbais e não verbais, a iconografia dos anúncios, a semiótica de seu projeto gráfico e até mesmo a lógica do seu sistema produtivo. Em suma, tratase de um todo complexo para cuja plena interpretação a respeito do impacto que tem nas diversas conjunturas históricas não nos parece suficiente o olhar posto nesta ou naquela matéria ou editoria, neste ou naquele episódio de confronto com o 
poder, ou ainda nas variações que sofre ao sabor das circunstâncias factuais que atravessaram as injunções referidas no parágrafo anterior, mas numa perspectiva antropológica que estrutura as relações de contemporaneidade do jornal e de seu produto (inclusive as construções sígnicas da publicidade e da propaganda) com o momento histórico em que vive.

\section{Realidade, modernização e democracia}

Vista dessa forma, a revista Realidade não circunscreve seu papel na história do jornalismo no período pós-1964 "apenas" como um veículo que deu curso e sequenciamento a uma narrativa que recuperava os indícios de modernização dos veículos, como é possível deduzir do exercício acadêmico de análise da imprensa brasileira no período que se segue à II Guerra. Para José Marques de Melo, é nesse momento que os jornais adotam "padrões de eficiência operacional" e "critérios de qualificação profissional para compor seus quadros técnicos" (MELO, 1979, p. 33). Em outra oportunidade, afirmamos que o conjunto dessas transformações - que abarca mudanças gráficas e editoriais correspondia

aos novos padrões de consumo dos centros urbanos em torno dos quais operam os meios de comunicação. A imprensa, a partir daí, estará modernamente vinculada à dinâmica cultural (Faro, 1999, p. 75).

Tudo indica que esse processo veio ao encontro das mudanças vividas pelo país nos anos 50 e que abarcaram todas as formas de manifestação cultural, naturalmente com grande visibilidade na imprensa porque ela traduzia, no plano da percepção da nova realidade urbana e social do país, um estado geral de transformações que se articulavam no (e com o) sentido do moderno, isto é, em sintonia com a conjuntura de emancipação das formas de gosto e escolha.

Ao escrever sobre esse quadro, tendo como referência a revista Senhor - uma das publicações que mais deram expressão a essas transformações, diz Ruy Castro:

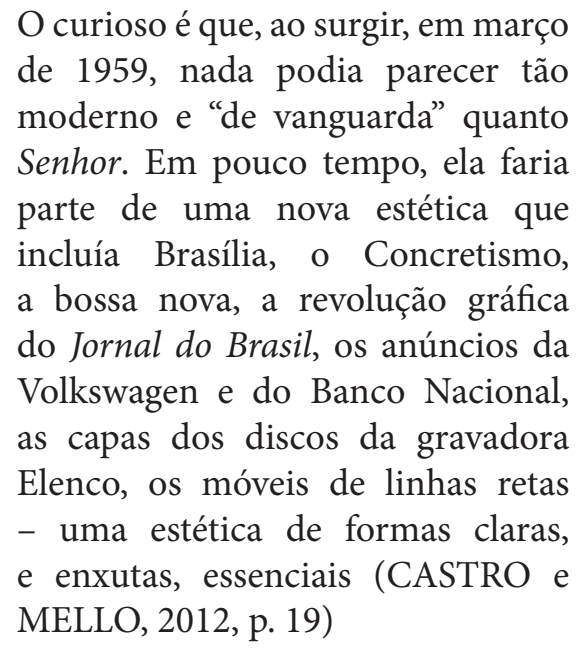

Vários dos estudos já desenvolvidos sobre a revista Realidade (TORRES, 2005; MORAES, 2010; OLIVEIRA, 2011; LEISTER FILHO, 2003) atestam essa dupla dimensão insinuada na análise de Castro e permitem deduzir que a revista herdava e sintetizava elementos simbólicos constitutivos do período do pós-guerra. A observação em perspectiva dessa conjuntura mostra um traço cultural hegemônico que acompanha a consolidação do bloco das nações capitalistas depois de 1945, conjunto ao qual pertence o Brasil, não sem um indisfarçável ar de contentamento pela inserção na modernidade de seus segmentos urbanos de média e alta renda. Em nossa opinião, não há nenhum componente da vida social brasileira que 
tenha ficado imune a essa conjuntura: ela se apresenta como plataforma política nos anos JK, como realidade econômica em mudança acelerada com o incremento do parque industrial; como processo de mudanças nas manifestações culturais, entre elas o Jornalismo. Neste último caso, numa linha tensionada de correspondência que guardava simetria com a modernização editorial de jornais e revistas e a emergência do novo cenário de valores ético-políticos e estéticoconceituais que davam preenchimento ao imaginário do público sob formas heterogêneas, diversas e plurais; transformações numa sociedade que abandonou de vez seu feitio interiorano e rural, espaço de legitimação do conservadorismo e do autoritarismo que o golpe de 64 inspirava, mas sobre cujos fundamentos sociais não tinha o controle: seu discurso moralista se alicerçava em núcleos semânticos (Deus, Pátria, Família) que iam no sentido inverso ao da dinâmica da modernização.

Quem bem definiu no terreno conceitual esse cenário de paradoxos capaz de motivar reações irreverentes até mesmo nos grandes jornais (Correio da Manhã e Jornal do Brasil, por exemplo) sobre os desacertos e trapalhadas da ordem unida dos militares foi Roberto Schwarz:

O governo que saia do golpe, contrariamente à pequena burguesia e à burguesia rural, que ele mobilizara mas não ia representar, não era atrasado. Era pró-americano e anti-popular, mas moderno. Levava a cabo a integração econômica e militar com os E.E.U.U. (sic), a concentração e a racionalização do capital. Neste sentido, o relógio não andara para trás e os expoentes da propriedade privada rural e suburbana não estavam no poder. Que interesse pode ter um tecnocrata, cosmopolita por definição, nos sentimentos que fazem a hinterlândia marchar? Muito mais interessante é ver o que vêm seus colegas em Londres, Nova York e Paris, Hair, Marat-Sade, Albee e mesmo Becht. Da mesma forma, quando marchavam pelas ruas contra o comunismo, em saia, blusa e salto baixo, as damas da sociedade não pretendiam renunciar às suas tualetes mais elaboradas. A burguesia entregou aos militares a Presidência da República e lucrativos postos na administração, mas guardava padrões internacionais de gosto $(1978$, p. 72$)$

\section{Espaços do jornalismo de Realidade entre as contradições do regime militar}

Em 1966, quando surgiu nas bancas, Realidade deu vida jornalística e estampou nas suas páginas essas contradições, pois que a ambivalência decorrente daquela conjuntura abria inúmeras possibilidades de apuração e investigação cujo efeito parece ter sido duplo, segundo entendemos. De um lado, a revista logo no início de sua existência se transformava em ícone do aggionarmento de seus leitores com a realidade do dia-a-dia e com o sentido imanente das coisas do cotidiano. Era em suas páginas que marcavam presença os itens da modernidade tardia brasileira, confusa e contraditória, itens assimétricos com o projeto autoritário que havia sido inaugurado dois anos antes. A riqueza do jornalismo produzido pela revista parece decorrer dessa sensibilidade com que sua redação conduzia um estado de 
percepção atinado para o movimento que caracterizou os anos 60, aqui e no exterior. Portanto, não é exatamente pelo perfil explícito e exclusivamente político de suas matérias que Realidade assume o lugar que tem na história do jornalismo brasileiro e que foi ocupado em conjuntura desfavorável (mas ainda possível então, até que viesse o arrocho do AI-5).

Analisadas de forma detida e contextualizadas, as matérias de perfil institucional $^{1}$ que a revista publicou não se caracterizaram exatamente por sua contundência e podem estar situadas em perspectiva distante de um jornalismo aguerrido ou contra-hegemônico, abertamente antigovernamental, como uma certa mitificação de Realidade acreditou ter existido ao longo dos anos em que ela se transformou em objeto de estudo. No entanto, é facilmente perceptível que há uma disposição editorial da publicação em dilatar a esfera de debates sobre questões sensíveis na conjuntura da época - e nos parece que isso, por si, já assegura o papel que sua produção jornalística teve na mobilização democrática.

A título de classificação das matérias conceituadas aqui como institucionais, cito três temáticas que revelam o sentido agônico das suas pautas, mas que foram tratadas a partir de uma sobriedade estilística que contorna o difícil distanciamento de enfoque, sem prejuízo de que pela própria natureza do assunto e pela forma como as matérias eram conduzidas (em especial, no caso de depoimentos e artigos com pontos de vista diversos) a argumentação em torno delas ganhasse dimensões públicas. A primeira delas, foi a da personificação (um ensaio prematuro de midiatização da política que o Brasil só conheceria décadas depois) do novo regime associada ao seu aparato jurídico antidemocrático e às novas orientações econômicas. Estão incluídas aqui as reportagens que põem em discussão um certo ufanismo militarista que antevê o país como potência hemisférica e global, assuntos que esbarravam nos conceitos mais delicados da Guerra-Fria em nome dos quais o golpe contra Jango recebeu parte de suas justificativas ${ }^{2}$.

A segunda temática dizia respeito aos opositores de primeira hora do novo regime: líderes políticos afastados da vida pública, cassados ou não, personalidades que simbolizavam os processos arregimentadores do populismo, debates que punham em juízo o novo sistema eleitoral, o novo quadro partidário, a possibilidade de que as restrições aos direitos civis se aprofundasse ${ }^{3}$.

A terceira temática vinha de um mergulho sobre a realidade social brasileira. Em inúmeras oportunidades, Realidade se debruçou na análise da vida das classes sociais subalternas, dos segmentos vitimados pelo processo embrutecedor da modernização do país e da concentração da renda, das fissuras sociais que ele provocava e do desencantamento público que isso trazia para o projeto integrador com o qual os militares acreditavam redimir o atraso da nação ${ }^{4}$.

No entanto, o quenos parece caracterizar Realidade como uma publicação que jogou papel editorial fundamental nos anos iniciais da mobilização democrática é a maneira aberta e contundente com que ela abordou os mais sensíveis processos simbólicos dos novos padrões
3- O termo institucional, tal como está sendo usado aqui, procura classificar reportagens, perfis, entrevistas, discussões promovidas nas páginas $d a$ revista, nas quais

Realidade abordou diretamente problemas ou personagens relacionados/ vinculados à estrutura do poder governamental e estatal.

4- Como exemplos: Eis Roberto Campos (abril de 1966), Feliz aniversário seu Artur (maio de 1966, sobre

Costa e Silva), Um garoto chamado

Artur (fevereiro de 1967, também sobre

Costa e Silva), Há um novo tempero no poder? (fevereiro de 1967), Dona Yolanda a presidenta (abril de 1967, sobre a Yolanda Costa e Silva), O Brasil deve enviar tropas para o Vietnã? (abril de 1968), O Brasil é um país imperialista?

(maio de 1968).

5- Como exemplos: Eleições indiretas são democráticas? (abril de 1966), Jânio, hoje (maio de 1966), É verdade que, no Brasil, todo o poder está nas mãos dos militares? (junho de 1966), Há liberdade no Brasil? (setembro de 1966), Os cassados têm o direito de defesa (novembro de 1966), Carlos Lacerda é um politico carreirista e incoerente? (março de 1968).

6- Como exemplos: Quanto custa o Brasil? (novembro de 1967), Eles vivem embaixo da terra (junho de 1967), Por que nosso trem não anda? (julho de 1967), Eles estão com fome (agosto de 1968), Os meninos do Recife (agosto de 1967), Existe racismo no Brasil? (agosto de 1968). 
7- Realidade foi pioneira no uso de pesquisas de opinião pública para estruturar suas pautas desde o lançamento do seu número zero (Faro, 1999, pp. 76, 77, 89) 8- São inúmeras as matérias que dão conta dessa rica pauta da revista Realidade. $\mathrm{Na}$ impossibilidade de referir-me a todas elas, recomendo a leitura daquelas que considero paradigmáticas (em ordem cronológica): Brasil: 60 milhões de pílulas por ano, maio de 1966, Desquite ou divórcio, julho de 1966, A juventude diante do sexo, agosto de 1966, os resultados da pesquisa feita pela revista sobre a opinião dos

brasileiros a respeito da dissolução do casamento (novembro de 1966), A educação sexual deveria ser obrigatória nas escolas? agosto de 1967, Sexo sem medo, novembro de 1968.

Possivelmente, $o$ caso que exemplifica com maior clareza essa tensão entre construções simbólico-culturais e o conservadorismo do aparelho estatal é o da apreensão da edição especial de Realidade publicada em janeiro de 1967 sobre o tema A mulher brasileira hoje.

Para uma descrição do episódio e seus desdobramentos político e jurídicos, sugiro a leitura do capitulo 7 (pgs. 126138) de Realidade, 1966-1968. Tempo da Reportagem na Imprensa Brasileira. Porto Alegre: Ulbral Age, 1999 (disponivel em http://tinyurl.com/ k3l3l35) de comportamento da primeira fase de sua existência (até dezembro de 1968) e cuja incorporação ao universo cognitivo dos leitores resultava em espaços de emancipação discursiva resistentes ao conservadorismo autoritário. Disso parece emergir o quadro descrito acima por Schwarz: uma hesitação do autoritarismo dos militares que favorecia uma sistemática excitação oposicionista, em especial nos segmentos médios dos principais centros urbanos do país. Segundo entendemos, era nessa brecha, por vários traços distintivos com que se destacou no panorama da imprensa brasileira da época (riqueza de códigos narrativos na fronteira com o new journalism e com a linguagem literária, sintonia de elementos verbais e nãoverbais na composição das matérias), e pela abrangência de suas pautas, que a publicação da Abril firmou-se como uma referência histórica. Quando Realidade é lembrada como divisor de águas no cenário histórico da imprensa brasileira, é a essas características que seus estudiosos se referem com maior ênfase.

As pautas relativas a esse segundo perfil de Realidade abrangem três temas que em cada uma das edições da revista em que foram tratados atuaram como catalisadores, a julgar pelo impacto que é possível perceber na repercussão que as matérias tiveram entre o público leitor - quando não foram exatamente produzidas a partir de pesquisas que procuravam identificar áreas de interesse do público alvo da revista ${ }^{7}$.

O primeiro desses temas é definido aqui como sendo o núcleo estruturante do discurso conservador que serviu como um dos elementos legitimadores do golpe de 1964 na sua articulação com a imprensa e com os segmentos sociais médios das grandes capitais, em especial São Paulo e Rio de Janeiro (as Marchas da Família). Trata-se de três sujeitos cuja articulação semântica constrói a pedra de toque do reacionarismo anticomunista que embalou a conspiração contra Goulart: a família, a mulher e o jovem. Realidade avançou sobre esses conceitos com rara contundência - e ineditismo - na imprensa brasileira -, desconstruindo-os e inserindo no âmbito de sua discussão a transgressão que marcava, em cada um deles, o zeitgeist dos anos 60: a dissolução do casamento, o divórcio, a liberdade individual de escolha, a emancipação feminina, o amor livre, a contracepção, o fim do mito da virgindade, o homossexualismo, o sexo na adolescência, o relaxamento das tensões comportamentais, a nova escola... ${ }^{8}$

Não é possível resgatar agora, senão como especulação, o peso que esse conjunto de afirmações trazidas a público nas matérias da revista teve no processo de mobilização democrática de outro tipo, pois que não diz respeito diretamente às instituições políticas, mas que dava vigor a um amplo contingente social que os militares só controlariam através da exacerbação dos mecanismos de repressão, entre eles a censura. Até que isso fosse possível em razão do agravamento da crise de representação que levou ao isolamento do governo (em dezembro de 1968), a revista da Abril atuou como plataforma concebida em convergência com a modernização, mas em dissonância com o autoritarismo.

O segundo tema, também articulado com os fundamentos do conservadorismo que levou ao golpe contra Jango, diz respeito à forma como Realidade tratou 
os desdobramentos, no âmbito da Igreja Católica, do Concílio Vaticano II. Em sucessivas reportagens e entrevistas, a revista abriu espaço para novas demandas de natureza teológica sobre o papel do Evangelho na emancipação social e política dos cidadãos, construção que alimentava entre o clero - até então disciplinado pela hierarquia conservadora da Igreja - uma opção militante, de aberta extração socialista, no sentido contrário ao papel reacionário que a instituição tinha desempenhado junto aos conspiradores de 1964. O caráter revelador das matérias que davam conta das novas disposições de Roma em torno do assunto esvaziou (ou mitigou) o peso que o tradicionalismo católico tinha na mobilização antidemocrática e convergia para o ambiente geral de contestação que marcou o período 9 .

No entanto, embora seja possível perceber a predominância de matérias relacionadas à Igreja Católica e, em especial, aos desdobramentos dos pontificados de João XXIII e de Paulo VI no Concílio Vaticano II - análises que interpretavam a progressiva politização

\section{Realidade produziu matérias que diziam respeito a espaços culturais em transição no cotidiano do público}

da atividade pastoral do clero e o peso que as decisões da reunião em Conselho Episcopal Latinoamericano (CELAM) tiveram na fundamentação da Teologia da Libertação -, as reportagens produzidas por Realidade sobre questões religiosas rompem também com o silêncio da produção jornalística brasileira sobre o sincretismo caracterizado em vários cultos praticados por segmentos sociais de extração popular, processo do qual sociedade brasileira tomava contato pelo caminho da Literatura e da Música, mais do que pelo caminho da imprensa. A revista da Abril rompeu com isso e, nessa medida, produziu matérias de elevada densidade sociológica ao tratar de manifestações situadas fora do domínio do catolicismo oficial, eventualmente associando-as a demandas políticas e comportamentais que quebravam a rigidez do conservadorismo ${ }^{10}$.

Por último, a revista da Abril produziu matérias que diziam respeito a espaços culturais em transição no cotidiano do público marcados pela ciência, pela educação, pelas atividades e práticas culturais em geral. Esse conjunto formava um painel de referências que compunha, com as temáticas anteriores, um quadro refratário aos tabus que se constituíam em matéria-prima da reação à adoção de valores mais consequentes com as sistemáticas novidades procedentes do ininterrupto processo de inovação científica, tecnológica, pedagógica, artística e comportamental que caracterizaram a época. Sobre isso, a revista mostrava, além de sintonia com o subtexto progressista dos fatos narrados, disposição de informação analítica e contextualizada.

Os exemplos, nesse sentido, são inúmeros, e em vários casos reiterativos de outras reportagens publicadas pela revista. É o caso de matérias que trataram
9- Trata-se de matérias nas quais toda a rigidez do pensamento católico tradicional, em seus vários ângulos, é posta em debate e posta em xeque sob a influência dos sinais que vinham de Paulo VI, do celibato dos sacerdotes (Sou padre e quero casar, setembro de 1966; O celibato, outubro de 1968) à militância estimulada pelo exemplo de D. Helder Câmara (O padre Helder, julho de 1966) e ao envolvimento dos dominicanos com os movimentos de protesto que se espalhavam pelo país (Revolução na Igreja, outubro de 1966,

Devem os sacerdotes participar diretamente das transformações sociais?, janeiro de 1968, O que querem estes padres, setembro de 1968). 10- Em especial: Um despacho de amor, julho de 1966; A benção, Sá Vigária, janeiro de 1967, Baixou o Santo, outubro de 1968. 
de questões biológicas relacionadas à mulher e que remetiam, para além de seu significado específico, a questões culturais de gênero abordadas em outros vários textos situados entre aqueles caracterizados aqui como integrantes do núcleo estruturante do pensamento conservador ${ }^{11}$ no Brasil. Em outro universo temático, matérias que contextualizavam processos científicos de larga repercussão à época ou o debate em torno de projetos educacionais que rompiam com a hegemonia da escola tradicional a partir de experiências brasileiras e internacionais ${ }^{12}$.

\section{Conclusões}

A mobilização democrática que ganha

11- Como exemplo dessa articulação discursiva, Os dias da criação, abril de 1966, A vida começa aqui, junho de 1966, A dor do parto não existe, junho de 1967, O aborto, junho de 1968, A cesariana, agosto de 1968. 12- À primeira vista, trata-se de uma clara dispersão temática; observada na lógica do processo de abertura que o projeto da revista ensaiou nos anos de sua maior coerência editorial, até 1968, é possivel perceber que Realidade oferece um roteiro de razoável coerência narrativa. corpo no país já nos primeiros meses posteriores ao golpe é um processo fragmentado e aparentemente desprovido de sentido programático, exceto quando se tratou de projeto orgânico concebido em termos partidários, mesmo assim fragilizado pelas sucessivas vagas repressoras e de fechamento institucional que inviabilizavam seu crescimento e amadurecimento no âmbito da sociedade civil. Essa característica pode explicar o sentido pendular das práticas políticas durante todo o período que se estende de 1964 a 1985 e que culminaram com a transição conciliadora observada mesmo depois de concluído o ciclo militar; uma redemocratização inconclusa, segundo entendemos. Nesse processo, em diversas oportunidades, o jornalismo desempenhou uma função tão importante quanto errática: ele repercutiu as tensões do Estado que se hipertrofiava mas, ao mesmo tempo, refletiu dificuldades de natureza institucional advindas do caráter privado dos veículos, alguns deles bastante comprometidos com a origem do sistema militar que se instalou no país. Se esses enunciados têm correspondência com a dinâmica política, é também possível perceber que Realidade, em razão de circunstâncias peculiares, associou às suas pautas aquilo que Maurício Vieira Martins designa como "excesso de significação" em relação ao fenômeno estético da obra de arte: "a capacidade de ultrapassar o estrito momento histórico em que foi produzido rumo a uma dimensão temporal mais ampla" (MARTINS, 2004). Os estudos disponíveis sobre a experiência da revista apontam nessa linha de intepretação: uma transcendência de abordagem como deve ser mesmo o jornalismo da grande reportagem feito com competência narrativa e investigativa, mas também processo de larga abrangência cultural que se insere no cotidiano do público; uma unidade de representação factual que arremetia sobre as dificuldades de toda ordem que decorreram da ruptura institucional de 64 .

Em nossa opinião, decorre dessas características o papel que Realidade teve nos anos nervosos e inquietos da mobilização democrática 


\section{Referências bibliográficas}

BRIGS, A. \& BURKE, P. (2004) Uma história social da mídia. Rio de Janeiro: Jorge Zahar Ed, 2004.

CASTRO, R. e MELlO, M.A. (2012). Sr. Uma senhora revista. São Paulo: Imprensa Oficial do Estado de São Paulo, 2012.

FARO, J.S. (1999). Revista Realidade, 1966-1968. Tempo da reportagem na imprensa brasileira. Porto Alegre: Ulbra/AGE, 1999.

HABERMAS, J. (1984). Mudança estrutural da esfera pública. Rio de Janeiro: Tempo Brasileiro, 1984.

LEISTER FILHO, A. (2003). Entre o sonho e a realidade: pioneirismo, ascensão e decadência da revista Realidade (1966-1976). Dissertação de Mestrado. São Paulo: FFLCH/USP, 2003.

MARQUES DE MELO, J. (1979). Poder, universidade e escolas de comunicação”. In Ideologia e Poder no Ensino de Comunicação. São Paulo: Cortez e Moraes/Intercom, 1979.

MARTINS, M. V. (2004) Bourdieu e o fenômeno estético: ganhos e limites de seu conceito de campo literário. In Revista Brasileira de Ciências Sociais, vol. 19, n. 56, outubro de 2004 (pp 63-74). São Paulo: ANPOCS, 2004.

MORAES, V. (2010). Realidade (re)vista: O papel do intelectual na concepção de um projeto revolucionário. Dissertação de Mestrado. Florianópolis: UFSC, 2010.

OLIVEIRA, J.C. (2011). A Revista Realidade: textos e contextos. Cadernos de Comunicação, vol. 15, n. 18. Porto Alegre: PUC-RS, 2011.

SCHWARZ, R. (1978). Cultura e Política, 1964-1969. In O pai de família e outros estudos. Rio de Janeiro: Paz e Terra, 1978.

TORRES, F. M. (2005). Revista Realidade (1966-1976): modelo de reportagem transitório entre as revisas ilustradas e de informação. In Ata Científica - Ciências Humanas. Maringá: Universidade Estadual de Maringá, 2005.

Este artigo e todo o conteúdo da Estudos em Jornalismo e Mídia estão

disponíveis em https://periodicos.ufsc.br/index.php/jornalismo

Estudos em Jornalismo e Mídia está sob a Licença Creative Commons 2.5 